\title{
Adhesion properties of human bladder cell lines with extracellular matrix components: the role of integrins and glycosylation
}

\author{
Anna Lityńska ${ }^{1, \bowtie}$, Małgorzata Przybyło ${ }^{1}$, Ewa Pocheć $^{1}$ and Piotr Laidler $^{2}$ \\ ${ }^{1}$ Department of Animal Physiology, Institute of Zoology, Jagiellonian University, Kraków, \\ Poland; ${ }^{2}$ Institute of Medical Biochemistry, Collegium Medicum, Jagiellonian University, \\ Kraków, Poland
}

Received: 02 January, 2002; revised: 25 June, 2002, accepted: 01 August, 2002

Key words: bladder cell lines, integrins, glycosylation, adhesion

\begin{abstract}
Integrin subunits present on human bladder cells displayed heterogeneous functional specificity in adhesion to extracellular matrix proteins (ECM). The non-malignant cell line (HCV29) showed significantly higher adhesion efficiency to collagen IV, laminin (LN) and fibronectin (FN) than cancer (T24, Hu456) and v-raf transfected (BC3726) cell lines. Specific antibodies to the $\alpha_{2}, \alpha_{5}$ and $\beta_{1}$ integrin subunits inhibited adhesion of the non-malignant cells, indicating these integrin participation in the adhesion to ECM proteins. In contrast, adhesion of cancer cells was not inhibited by specific antibodies to the $\beta_{1}$ integrin subunit. Antibodies to $\alpha_{3}$ integrin increased adhesion of cancer cells to collagen, LN and FN, but also of the HCV29 line with colagen. It seems that $\alpha_{3}$ subunit plays a major role in modulation of other integrin receptors especially in cancer cells. Differences in adhesion to ECM proteins between the non-malignant and cancer cell lines in response to Gal and Fuc were not evident, except for the v-raf transfected cell line which showed a distinct about 6-fold increased adhesion to $\mathrm{LN}$ on addition of both saccharides. $N$-Acetylneuraminic acid inhibited adhesion of all cell lines to LN and FN irrespective of their malignancy.
\end{abstract}

Many studies have attributed the altered adhesive behaviour of tumour and transformed cells to changes in the expression pattern and affinity of their integrins (Morini et al., 2000;
Schramm et al., 2000). Most integrins are able to bind various ligands with different affinities. The high affinity state of an integrin for its ligand may be a constitutive condition depend-

\footnotetext{
This work was supported by the grants from Jagiellonian University: BW/IZ/44/2000 and DS/IZ/ FZ/2000.

${ }^{凶}$ Corresponding author. Department of Animal Physiology, Institute of Zoology, Jagiellonian University, R. Ingardena 6, 30-060 Kraków, Poland; fax: (48 12) 634 3716; e-mail: Lita@zuk.iz.uj.edu.pl
}

Abbreviations: ECM, extracellular matrix; FN, fibronectin; Fuc, fucose; Gal, galactose; LN, laminin; NeuAc, $N$-acetylneuraminic acid. 
ing on the cell type, or may be induced by signalling through other cells surface receptors (Ivaska \& Heino, 2000). Rapid upregulation of the integrin function is induced by numerous stimuli acting either from outside the cell or from its interior (Humphries, 1996). The interactions of cells with extracellular matrix (ECM) depend on the expression and function of integrin receptors. On the other hand, changes in the expression and structure of carbohydrates may be considered as a universal feature of malignant transformation. It is known that protein-carbohydrate interactions play a crucial role in recognitive events. In particular, galectins that specifically bind $\beta$ galactose residues have been implicated as modulators of cell adhesion, since they are secreted into the extracellular space and cross-link the glycoconjugates on the cell surface and ECM proteins, most probably laminin (LN) (Zhou \& Cummings, 1993) and fibronectin (FN) (Ozeki et al., 1995). In accordance with the proposed function galectins enhance (Kuwabara \& Liu, 1996) or inhibit (Hadari et al., 2000) cell matrix interactions. Carbohydrate-based recognition occurring on the cell surface depends also on the presence of sialic acid residues, which potentially can inhibit intermolecular and intercellular interactions due to their negative charge. However, they can also act as ligands recognised by a variety of sialic acid binding lectins (Kim \& Varki, 1997). Also sialyl Lewis ${ }^{\text {a }}$ antigens are implicated in the adhesion of human cancer cells (Ugorski \& Laskowska, 2002).

The results of flow cytometry of the same human non-malignant ureter epithelium (HCV29), malignant human bladder carcinoma (T24, HU456) and v-raf transfected HCV29 (BC3726) cell lines (Laidler et al., 2000) indicated significant differences in expression of the $\beta_{1}$ integrin subunit in cell lines irrespective of their malignancy and nonsignificant differences in the expression of the $\alpha_{2}, \alpha_{3}$ and $\alpha_{5}$ subunits between malignant and non malignant cell lines. To specify more closely the role of these integrins in the progression of the transitional bladder cancer we have extended our studies to the adhesion efficiency assays of the above cell lines to collagen type IV, $\mathrm{LN}$ and $\mathrm{FN}$, using specific anti-integrin antibodies and also three monosaccharides, i.e. fucose (Fuc), galactose (Gal) and $N$-acetylneuraminic acid (NeuAc), affecting cell adhesion.

\section{MATERIALS AND METHODS}

Chemicals. PVDF membranes were from Millipore. Collagen IV, fibronectin, laminin, bovine serum albumin (BSA) solution, crystal violet, proteinase inhibitor cocktail, and fucose were from Sigma Chemical Co. Galactose and $N$-acetylneuraminic acid were from Serva. All remaining chemicals were of analytical grade.

Monoclonal antibodies. The following monoclonal antibodies (mAbs) were used: specific to the $\alpha_{2}$ (clone P1E6) and $\alpha_{3}$ (clone P1B5) integrin subunits (DAKO); specific to the $\alpha_{5}$ (clone $\mathrm{CDw} 49 \mathrm{e}$ ) and $\beta_{1}$ (clone CD29/ GPIIa) subunits (Genosys Biotechnologies).

Cell lines and culture conditions. The following cell lines were used: non-malignant transitional epithelial of ureter, HCV29, and transitional cancer of ureter bladder, Hu456 (Vilien et al., 1983), T24 (HTB-4, ATCC (Bubenick et al., 1973)), and v-raf transfected HCV29 line, BC3726. These cell lines were obtained from the Cell Line Collection of the Institute of Immunology and Experimental Therapy, Polish Academy of Sciences (Wrocław, Poland). The cell lines were cultured in RPMI 1640 medium (Sigma Chemical Co.) containing $10 \%$ fetal bovine serum (FBS) (GibcoBRL $^{\mathrm{TM}}$ or Boehringer) and antibiotics (penicilin - $100 \mathrm{U} / \mathrm{ml}$, streptomycin - 100 $\mu \mathrm{g} / \mathrm{ml}$, Polfa Tarchomin, Poland). The cells were grown in monolayers in a $95 \%$ air $/ 5 \%$ $\mathrm{CO}_{2}$ atmosphere at $37^{\circ} \mathrm{C}$ in a humidified incubator.

Cell adhesion assay. 96-well culture plates (Costar) coated alternatively with $10 \mu \mathrm{g} / \mathrm{ml}$ collagen IV, LN or FN were blocked for $90 \mathrm{~min}$ 
at $37^{\circ} \mathrm{C}$ with $1 \%$ heat-denatured BSA. Next the wells were washed twice with phosphate-buffered saline (PBS) and once with RPMI 1640 to remove the excess of BSA prior to the addition of cells. Before the adhesion assay, cells were washed in serum-free medium and starved for $30 \mathrm{~min}$. Cells were trypsinized and reseeded at a density of $5 \times 10^{4}$ cells per well on the different matrix proteins. Cells were allowed to adhere for $30 \mathrm{~min}$ at $37^{\circ} \mathrm{C}$ in a $\mathrm{CO}_{2}$ incubator. Non-adherent cells were removed by washing three times with PBS. Adherent cells were fixed for $10 \mathrm{~min}$ in $96 \%$ ethanol, washed three times in PBS, stained with $0.1 \%$ crystal violet for $25 \mathrm{~min}$, washed in tap water and air-dried. Stained cells were lysed overnight on a shaker in $0.5 \%$ Triton X-100 to release the dye. The absorbance at $600 \mathrm{~nm}$ determined using an ELISA-reader $\left(\mathrm{El}_{\mathrm{x}} 808_{\mathrm{IV}}\right.$ Ultra Microplate Reader, Bio Tek Instruments) was proportional to cell numbers (Kueng et al., 1989). Each data point was calculated from two separate experiments performed in triplicate and was expressed as the mean \pm standard deviation (S.D.). Non-specific cell adhesion as measured on BSA-coated wells was subtracted.

For competition experiments, cells were preincubated with monoclonal antibodies against protein coated wells. After pre-incubation with mAbs, cell viability was higher than $97 \%$. The antibody remained present during the assay. Control competitions with non-specific IgG had no effect on adhesion.

In order to study the participation of carbohydrate moieties of the cell surface glycoproteins as well as ECM proteins in the adhesion process, we analysed the adhesion efficiency of the cells to $\mathrm{LN}$ and $\mathrm{FN}$ in the presence of $0.1 \mathrm{M}$ Fuc, Gal or NeuAc solutions in PBS.

Statistics. The significance of the differences between mean values were computed using Dunkan's new multiple range test $\left({ }^{*} P<0.05\right.$ or $\left.{ }^{*} P<0.01\right)$.

Other methods. Protein was determined by the Comassie Brilliant Blue-binding assay method (Bradford, 1976) using bovine serum albumin as standard.

\section{RESULTS}

\section{Cell adhesion}

The cell lines examined attached to collagen IV, LN and FN with different efficiencies (Fig. 1). The adhesion efficiency of the normal

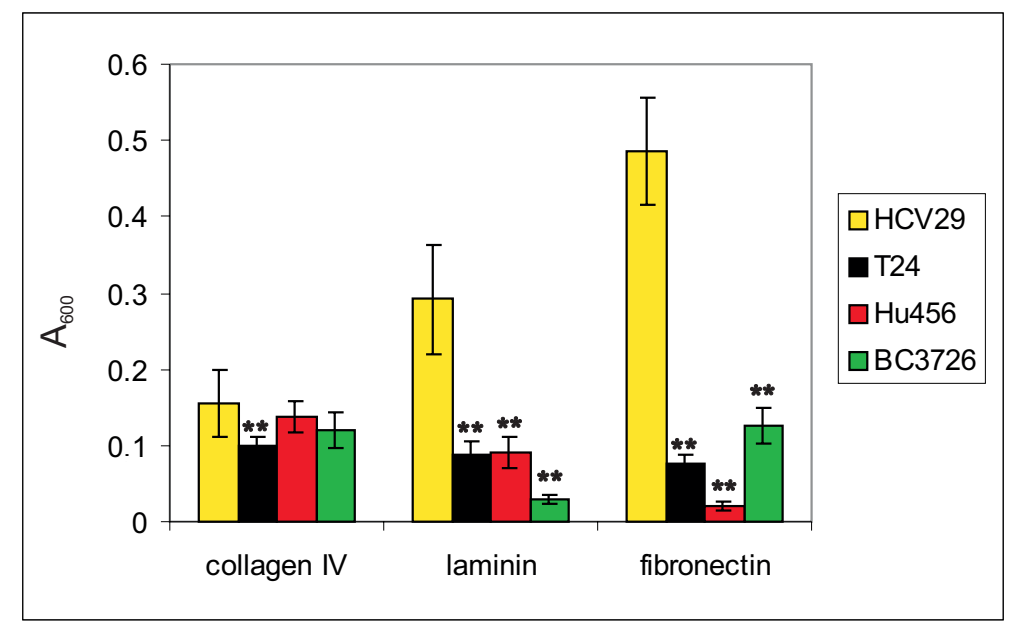

Figure 1. Adhesion of human non-malignant HCV29 and malignant T24, Hu456, and BC3726 cells to collagen IV, laminin and fibronectin.

Cell adhesion is presented as absorbance units (A) at $600 \mathrm{~nm}$. Values are expressed as mean \pm standard deviation of two independent experiments performed in triplicate. Bars indicate S.D. and ${ }^{*} P<0.05$ and ${ }^{* *} P<0.01$.

the $\alpha_{2}, \alpha_{3}, \alpha_{5}$ or $\beta_{1}$ integrin subunits at a concentration of $1.4 \mu \mathrm{g} / \mathrm{ml}, 2 \mu \mathrm{g} / \mathrm{ml}, 1.2 \mu \mathrm{g} / \mathrm{ml}$ and 1.5 $\mu \mathrm{g} / \mathrm{ml}$, respectively, on a shaker at room temperature for $30 \mathrm{~min}$ prior to seeding on matrix
HCV29 cells to all ECM proteins was significantly higher than that of T24, Hu456 and BC3726 cells, except for Hu456 and BC3726 cells adhesion to collagen IV. 


\section{Effect of monoclonal antibodies on cell adhesion}

In order to assess whether $\alpha_{2} \beta_{1}, \alpha_{3} \beta_{1}, \alpha_{5} \beta_{1}$ or other integrins of the $\beta_{1}$ integrin family were responsible for mediating adhesion to collagen IV, LN or FN, cell adhesion assays were performed in the presence of specific anti-integrin monoclonal antibodies.

As shown in Fig. 2A, mAb P1A6 to the $\alpha_{2}$ subunit inhibited Hu456 and BC3726 cells ad-
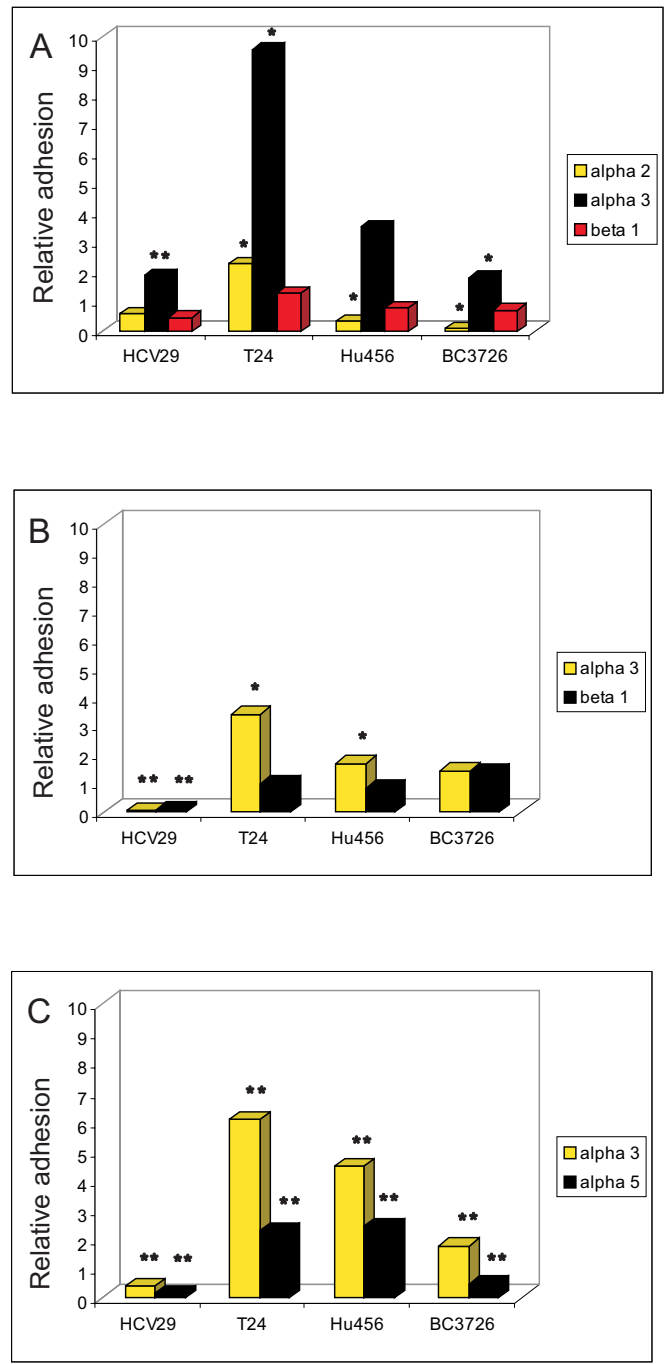

Figure 2. Effect of monoclonal antibodies to $\alpha_{2}$, $\alpha_{3}, \alpha_{5}$ and $\beta_{1}$ integrin subunits on adhesion of HCV29, T24, Hu456 and BC3726 cells to collagen IV (A), laminin (B) and fibronectin (C).

Cell adhesion of cells adhering in the presence of the indicated antibodies is presented relatively to control adhesion (cells without additions). Each result is the average of two independent experiments performed in triplicate. Relative to control taken as one. ${ }^{*} P<0.05$ and ${ }^{* *} P<0.01$. hesion to collagen IV, increased attachment of T24 cells, but had no effect on HCV29 cells adhesion level. In contrast, mAb P1B5 to $\alpha_{3}$ subunit increased adherence of all cells to collagen IV (Fig. 2A). On the other hand, $\mathrm{mAb}$ CD29/GPIIa to $\beta_{1}$ subunit had no effect on any cells adhesiveness to collagen IV (Fig. 2A). Similarly, this mAb did not affect the ability of T24, Hu456 or BC3726 cells to adhere to LN, but caused a decline in HCV29 cell adhesion to LN (Fig. 2B).

mAb P1B5 to the $\alpha_{3}$ subunit inhibited HCV29 cells attachment to $\mathrm{LN}$ and FN (Fig. 2B, C). However, this mAb had an opposite effect on T24 and Hu456 cells adhesion level to $\mathrm{LN}$ and $\mathrm{FN}$, failed to affect BC3726 cell adhesion to LN and caused an increase in the attachment to FN (Fig. 2B, C). Similarly, mAb CDw49e to the $\alpha_{5}$ subunit inhibited HCV29 and BC3726 cells attachment to FN and increased T24 and Hu456 cells binding (Fig. 2C). Incubation of cells with non-specific IgG did not influence binding to collagen IV, LN nor FN (not shown).

\section{Effect of monosaccharides on cell adhesion to $\mathrm{LN}$}

A significant effect was observed in the case of NeuAc, whose presence decreased or completely reduced adhesion to $\mathrm{LN}$ of all the cell lines tested (Fig. 3A). Attachment of HCV29 cells was also inhibited in the presence of Gal or Fuc, by about $21 \%$ and $52 \%$ of control level (Fig. 3A). In the case of the cancer cell lines (T24, Hu456) the presence of Gal or Fuc inhibited or had no effect on adhesion to LN (Fig. 3A). On the other hand, addition of Gal and Fuc caused a significant increase in the attachment of BC3726 cells to LN (Fig. 3A).

\section{Effect of monosaccharides on cell adhesion to FN}

Similar as in the case of LN-binding NeuAc, reduced adhesion of all the cell lines tested to 

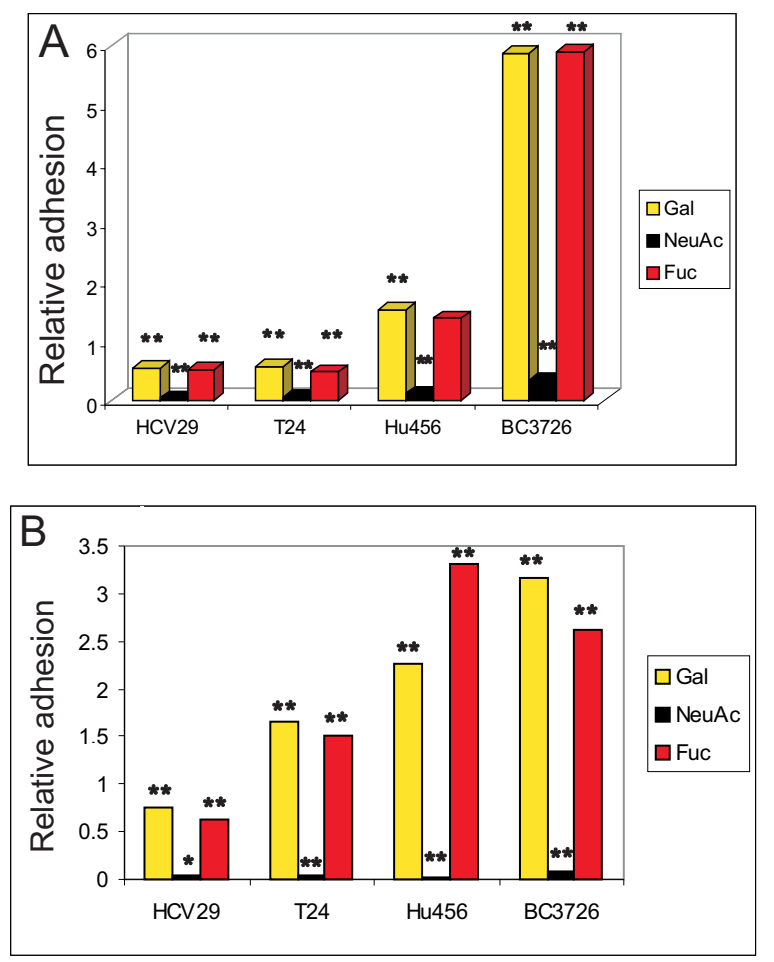

Figure 3. Influence of different monosaccharides on adhesion of HCV29, T24, Hu456 and BC3726 cells to laminin (A) and fibronectin (B).

Cell adhesion was measured in the presence of $0.1 \mathrm{M}$ solutions of Gal, NeuAc or Fuc. Cell adhesion is presented relatively to control adhesion (cells without additions). Each result is the average of two independent experiments performed in triplicate. Relative to control taken as one. ${ }^{*} P<0.05$ or ${ }^{* *} P<0.01$.

FN to $0-9 \%$ of control level (Fig. 3B). Adhesion of HCV29 cells was inhibited or reduced by Gal and Fuc as in the case of LN (Fig. 3B). Surprisingly, the cancer cells in the presence of Gal or Fuc adhered more efficiently to FN (Fig. 3B). The BC3726 cells behaved in the same way as on LN being more adhesive in the presence of both this monosaccharides.

\section{DISCUSSION}

Our results show that adherence of human bladder non-malignant HCV29 cells to collagen IV, LN and FN is higher than of cancer cells. It is known that the interactions between cells and ECM proteins largely depend on the expression of functional integrins on the cell surface, mainly of the $\beta_{1}$ integrin family (Curley et al., 1999). Adhesion of non-malignant cells was inhibited by antibodies against the $\beta_{1}, \alpha_{2}, \alpha_{3}$ and $\alpha_{5}$ integrin subunits indicating that these integrins are important receptors in non-malignant cells. These results are consistent with those of Heino (2000) and Nykvist et al. (2000) that the $\alpha_{1} \beta_{1}$ and $\alpha_{2} \beta_{1}$ integrins are high-affinity receptors for type IV collagen, while according to Akiyama et al. (1995) integrin $\alpha_{5} \beta_{1}$ is the major FN receptor for most cells. A lack or even reverse response characteristic for cancer human bladder cells to anti-integrin antibodies requires an explanation.

A single cell type may express multiple integrins with an apparently redundant ligand specificity. The functional significance of this redundancy is not understood but it is clear that different binding sequences are recognised by separate receptors that may function cooperatively and each can lead to different cellular response. Signalling events initiated by the occupancy of one integrin can suppress functions associated with other integrins, a process known as integrin cros-talk, e.g. integrin $\alpha_{\mathrm{v}} \beta_{3}$ and $\alpha_{5} \beta_{1}$ (Blyston et al., 1994; 1999; Simon et al., 1997). Positive and negative co-operation as well as trans-dominant inhibition have been described for several integrins (Diaz-Gonzales et al., 1996).

Our results allow us to conclude that in the human bladder, multiple receptors contribute to cell adhesion to ECM proteins and each cell line uses different repertoire of these receptors, as manifested distinctly in cancer cells. This would imply that adhesion of tumour cells is mediated by other integrins, possibly also from a non- $\beta_{1}$ family, e.g. by $\alpha_{\mathrm{v}} \beta_{3}$ which like $\alpha_{5} \beta_{1}$ can serve as an $\mathrm{FN}$ receptor.

At least fifteen different molecules have been described as either $\mathrm{LN}$ receptor or LN-binding protein, including several members of the integrin family (Belkin \& Stepp, 2000). The specificity of integrin $\alpha_{3} \beta_{1}$ for its ligands depends on the presence of other integrins that may display a higher activity 
for the same ligands (Kreidberg, 2000; Laplantine et al., 2000). There is growing amount of evidence that integrin $\alpha_{3} \beta_{1}$ transdominantly regulates integrin $\alpha_{6} \beta_{1}$ in mouse keratinocytes (Hodivala-Dilke et al., 1998; Laplantine et al., 2000) or regulates negatively integrin $\alpha_{2} \beta_{1}$ in human breast carcinoma cell lines (Lichtner et al., 1998). Our results confirmed the major role for the $\alpha_{3} \beta_{1}$ integrin in modulating other adhesion receptors especially in the case of cancer cell lines like T24 and Hu456. However, the mechanism of the postulated shift or cooperation in integrins interaction in malignant cells remains unknown.

Besides, although integrin-mediated adhesion to $\mathrm{FN}$ and $\mathrm{LN}$ is based on interaction of specific amino-acid residues, the strength of the binding may be modulated by various factors including glycosylation of integrins (Chammas et al., 1993; Zheng et al., 1994), glycosylation status of ECM proteins (Zheng \& Hakomori, 2000) as well as carbohydrate-carbohydrate interactions (Wang et al., 2001).

We observed uniform decrease of adhesion of all the cell lines to LN and FN in the presence of NeuAc. These results suggest the participation of NeuAc-bearing glycans in the adhesion to $\mathrm{LN}$ and FN regardless of cell type. The high sensitivity of all cell lines to NeuAc does not allow one to consider inhibition of adhesion by NeuAc as a factor discriminating non-malignant from malignant cell lines. According to Morgenthaler et al. (1990) and Dennis (1991) NeuAc affects attachment to ECM proteins either by their masking or as a recognition determinant (Morgenthaler et al., 1990; Dennis, 1991). Also in the case of FN it can not be excluded that sialic acid competes with polysialic acid, a very important component of $\alpha_{5}$ integrin oligosacccharides participating in adhesion to this ECM protein as has recently been shown (Nadanaka et al., 2001).

The alterations in the adhesion efficiencies of the cell lines in response to Gal and Fuc were cell- and ligand-dependent. The presence of Gal or Fuc decreased adhesion efficiency to LN in the non-malignant HCV29 and T24 malignant cells, while it was increased in BC3726 cells. $\mathrm{LN}$ is a heavily glycosylated molecule with only N-linked complex-type oligosaccharides containing poly- $N$-acetyllactosamine units. Due to its unique glycosylation pattern LN can be also recognised by cell surface $\beta 1-4$ galactosyltransferase and several members of the galactoside-binding lectin family (Chammas et al., 1994). On the other hand, LN may function as a lectin, recognising carbohydrate moieties of the receptor as it has been shown by Chammas et al. (1991) in metastatic murine melanoma.

Ono et al. (2000) have found that LN or FN-dependent adhesion in Krieger's D14 cells was enhanced significantly in the presence of Gal. Tunicamycin significantly inhibited adhesion to LN but only slightly affected cell adhesion to collagen IV of metastatic melanoma cell lines (Bironaite et al., 2000). On the other hand, mouse myoblasts did not distinguish between glycosylated and unglycosylated LN substrates indicating that LN carbohydrates are not implicated in those cellular responses (Kostrominova \& Tanzer, 1995). These facts although controversial, suggest that glycosylation of LN as well as of surface proteins are important in adhesion events, but as it was shown in our study it takes place in a cell-type dependent manner.

The distinctly different adhesion of BC3726 cells to $\mathrm{LN}$ and $\mathrm{FN}$ in the presence of monosaccharides compared with the other cell lines may suggest significant changes in properties of the cellular membrane proteins due to v-raf transfection.

From all these results we can conclude that the behaviour of non-malignant bladder cells differs significantly from that of cancer ones with respect to the integrins used as well as the participation of saccharides in adhesion. The cancer cells showed a more veriable pattern of cell adhesion. 


\section{R E F E R E N C E S}

Akiyama SK, Olden K, Yamada KM. (1995) Fibronectin and integrins in invasion and metastasis. Cancer Metast Rev.; 14: 173-89.

Belkin AM, Stepp MA. (2000) Integrins as receptor for laminins. Microscopy Res Tech.; 51: 280-301.

Bironaite D, Nesland JM, Dalen H, Risberg B, Bryne M. (2000) N-glycans influence the in vitro adhesive and invasive behaviour of three metastatic cell lines. Tumor Biol.; 21: $165-75$.

Blyston SD, Graham IL, Lindberg FP, Brown EJ. (1994) Integrin $\alpha_{\mathrm{v}} \beta_{1}$ differentially regulates adhesive and phagocytic functions of the fibronectin receptor $\alpha_{5} \beta_{1}$. J Cell Biol.; 127: $1129-37$.

Blyston SD, Slater SE, Williams MP, Crow MT, Brown EJ. (1999) A molecular mechanism of integrin crosstalk: $\alpha_{\mathrm{v}} \beta_{3}$ suppression of calcium/calmodulin-dependent protein kinase II regulates $\alpha_{5} \beta_{1}$ function. $J$ Cell Biol.; 145: 889-97.

Bradford MM. (1976) A rapid and sensitive method for quantitation of microgram quantities of protein utilising the principle of protein-dye binding. Anal Biochem.; 72: 248-54.

Bubenick J, Baresova M, Viklicky V, Jakoubkova J, Sainerova H, Donner J. (1973) Established cell line of urinary bladder carcinoma (T24) containing tumor specific antigen. Int $J$ Cancer:; 11: 765-73.

Chammas R, Veiga SS, Line S, Potocnjak P, Brentani RR. (1991) Asn-linked oligosaccharide dependent interaction between laminin and gp 120/140. An $\alpha_{6} \beta_{1}$ integrin. $J$ Biol Chem.; 266: 3349-55.

Chammas R, Veiga SS, Travassos LR, Brentani RR. (1993) Functionally distinct roles for glycosylation of $\alpha$ and $\beta$ integrin chains in cell-matrix interactions. Proc Natl Acad Sci U S A.; 90: 1795-9.

Chammas R, Jasiulionis MG, Jin F, Villa-Verde DMS, Reinnhold VN. (1994) Carbohydrate-binding proteins in cell-matrix interac- tions. Brazilian J Mad Biol Res.; 27: 2169-79.

Curley GP, Blum H, Humphries MJ. (1999) Integrin antagonists. Cell Mol Life Sci.; 56: $427-41$.

Dennis JW. (1991) N-linked oligosaccharide processing and tumor cell biology. Cancer Biol.; 2: 411-20.

Diaz-Gonzales F, Forsyth J, Steiner B, Ginsberg MK. (1996) Trans-dominant inhibition of integrin function. Mol Biol Cell; 7: 1939-51.

Hadari YR, Arbel-Goren R, Levy Y, Amsterdam A, Alon R, Zakut R, Zick Y. (2000) Galectin-8 binding to integrins inhibits cell adhesion and induces apoptosis. $J$ Cell Sci.; 113: 2385-97.

Heino J. (2000) The collagen receptor integrins have distinct ligand recognition and signaling function. Matrix Biology.; 19: 319-23.

Hodivala-Dilke KM, DiPersio CM, Kreidberg JA, Hynes RO. (1998) Novel role for $\alpha 3 \beta 1$ integrin as a regulator of cytoskeletal assembly and as a trans-dominant inhibitor of integrin receptor function in mouse keratinocytes. J Cell Biol.; 142: 1357-69.

Humphries MJ. (1996) Integrin activation: the link between ligand binding and signal transduction. Curr Opin Cell Biol.; 8: 632-40.

Ivaska J, Heino J. (2000) Adhesion receptors and cell invasion: mechanisms of an integrin-guided degradation of extracellular matrix. Cell Mol Life Sci.; 57: 16-24.

Kim YJ, Varki A. (1997) Perspectives on the significance of altered glycosylation of glycoproteins in cancer. Glycoconjugates J.; 14: $569-76$.

Kreidberg JA. (2000) Functions of $\alpha 3 \beta 1$ integrin. Curr Opin Cell Biol.; 12: 548-53.

Kueng W, Silber E, Eppenberger U. (1989) Quantification of cells culture on 96-well plates. Anal Biochem.; 182: 16-9.

Kuwabara I, Liu FT. (1996) Galectin-3 promotes adhesion of human neutrophils to laminin. $J$ Immunol.; 156: 3939-44. 
Kostrominova TY, Tanzer ML. (1995) Rodent myoblasts interactions with laminin require cell surface glycoconjugates but not laminin glycosyl groups. J Cell Biochem.; 57:163-72.

Laidler P, Gil D, Pituch-Noworolska A, Ciołczyk D, Książek D, Przybyło M, Lityńska A. (2000) Expression of $\beta_{1}$-integrins and $\mathrm{N}$-cadherin in bladder cancer and melanoma cell lines. Acta Biochim Polon.; 47: 1159-70.

Laplantine E, Vallar L, Mann K, Kieffer K, Aumailley M. (2000) Interaction between the cytodomains of $\alpha_{3}$ and $\beta_{1}$ integrin subunits regulates remodelling of adhesion complex on laminin. J Cell Sci.; 113: 1167-76.

Lichtner RB, Howlett AR, Lerch M, Xuan JA, Brink J, Langton-Webster B, Schneider R. (1998) Negative cooperativity between $\alpha_{3} \beta_{1}$ and $\alpha_{2} \beta_{1}$ integrins in human mammary carcinoma MDA MB 231 cells. Exp Cell Res.; 240: 368-76.

Morini M, Mottolese M, Ferrari N, Ghiorzo F, Buglioni S, Mortarini R, Noonan DM, Natali PG, Albini A. (2000) The $\alpha_{3} \beta_{1}$ integrin is associated with mammary carcinoma cell metastasis, invasion, and gelatinase B (MMP-9) activity. Int $J$ Cancer.; 87: 336-42.

Morgenthaler J, Kemmner W, Brossmer R. (1990) Sialic acid dependent cell adhesion to collagen IV correlates with in vivo tumorogenicity of the cell human colon carcinoma sublines HCT116, HCT116a and HCT116b. Biochem Biophys Res Commun.; 171: $860-6$.

Nadanaka S, Sato Ch, Kitajima K, Katagiri K, Irie S, Yamagata T. (2001) Occurence of oligosialic acids on integrin $\alpha_{5}$ subunit and their involvement in cell adhesion to fibronectin. J Biol Chem.; 276: 33657-64.

Nykvist P, Tu H, Ivaska J, Kapyla J, Pihlajaniemi T, Heino J. (2000) Distinct recognition of collagen by $\alpha_{1} \beta_{1}$ and $\alpha_{2} \beta_{1}$ integrins. J Biol Chem.; 275: 8255-61.

Ono KA, Handa K, Hakomori S. (2000) Glycosylation affects translocation of integrins, Src, and caveolin into or out of GEM. Biochem Biophys Res Commun.; 273: 159-63.

Ozeki Y, Matsui T, Yamamoto Y, Funahashi M, Hamako J, Titani K. (1995) Tissue fibronectin is an endogenous ligand for galectin-1. Glycobiology.; 5: 255-61.

Schramm K, Krause K, Bittroff-Leben A, Goldin-Lang P, Thiel E, Kreuser E-D. (2000) Activated K-ras is involved in regulation of integrin expression in human colon carcinoma cells. Int $J$ Cancer.; 87: 155-64.

Simon KO, Nutt EM, Abraham DG, Rodan GA, Duong LT. (1997) The $\alpha_{v} \beta_{3}$ integrin regulates $\alpha_{5} \beta_{1}$-mediated cell migration toward fibronectin. J Biol Chem.; 46: 29380-9.

Ugorski M, Laskowska A. (2002) Sialyl Lewis ${ }^{a}$ : a tumor-associated carbohydrate antigen involved in adhesion and metastatic potential of cancer cells. Acta Biochim Polon.; 49: 303-11.

Vilien M, Christensen B, Wolf H, Rassmussen F, Hou-Jensen C, Povlsen CO. (1983) Comparative studies of normal, 'spontaneously' transformed and malignant human urothelium cells in vitro. Eur $J$ Cancer Clin Oncol.; 19: 775-89.

Wang X, Sun P, Al-Qamari A, Tai T, Kawashima I, Paller AS. (2001) Carbohydrate-carbohydrate binding of ganglioside to integrin $\alpha_{5}$ modulates $\alpha_{5} \beta_{1}$ function. $J$ Biol Chem.; 276: 8436-44.

Zheng M, Hakomori S. (2000) Soluble fibronectin interaction with cell surface and extracellular matrix is mediated by carbohydrate-to-carbohydrate interaction. Arch Biochem Biophys.; 373: 93-9.

Zheng M, Fang H, Hakomori S. (1994) Functional role of $\mathrm{N}$-glycosylation in $\alpha_{5} \beta_{1}$ integrin receptor. J Biol Chem.; 269: 12325-31.

Zhou Q, Cummings RD. (1993) L-14 lectin recognition of laminin and its promotion of in vitro cell adhesion. Arch Biochem Biophys.; 300: $6-17$. 